\title{
Efeitos da Adição de Inoculantes Microbianos sobre o Perfil Fermentativo da Silagem de Alfafa Adicionada de Polpa Cítrica ${ }^{1}$
}

\author{
Paulo Henrique Mazza Rodrigues ${ }^{2,4}$, Luis Fernando Simões de Almeida ${ }^{3}$, Carlos de Souza \\ Lucci $^{2}$, Laércio Melotti ${ }^{2}$, Félix Ribeiro de Lima ${ }^{2}$
}

\begin{abstract}
RESUMO - A cultura de alfafa (19\% de MS), cortada com 10\% dos perfilhos floridos, foi armazenada em 32 silos experimentais confeccionados a partir de baldes plásticos portando válvulas. A alfafa picada foi homogeneizada e submetida a quatro tratamentos com ou sem a adição de $12 \%$ de polpa cítrica peletizada: controle, Sil-All® (S. faecium, P. acidilactici, L. plantarum, amilase, hemicelulase e celulase), Silobac ${ }^{\circledR}$ (L. plantarum, S. faecium e Lactobacillus sp.) e Pioneer 1174® (S. faecium e L. plantarum). Os silos foram abertos após 133 dias para análise da composição bromatológica, perfil fermentativo e estabilidade aeróbia. Apenas na silagem não adicionada de polpa, todos os inoculantes aumentaram os teores de etanol, o Pioneer aumentou o pH e o Silobac reduziu a concentração de ácido acético. Independentemente da presença de polpa, todos os inoculantes diminuíram as perdas de MS; o Silobac e o Pioneer diminuíram a DIVMS e o Pioneer aumentou o $\mathrm{N}_{-} \mathrm{NH}_{3}$. Os inoculantes não afetaram as concentrações dos ácidos lático, propiônico ou butírico, bem como a estabilidade aeróbia, independentemente da presença da polpa. De forma geral, a adição de polpa cítrica melhorou a composição bromatológica e o perfil fermentativo, mas piorou as perdas e a estabilidade aeróbia.
\end{abstract}

Palavras-chave: ácidos orgânicos, bactérias láticas, ensilagem, Medicago sativa

\section{Effects of Microbial Inoculants on Chemical Composition and Fermentation Characteristics of Alfalfa Silage Added with Citrus Pulp}

\begin{abstract}
Alfalfa crop (19.0\% DM) was harvested at 35 days and ensiled in 32 plastic experimental silos, consisting of four treatments with or without $12 \%$ of citrus pulp: control, Sil-All® (S. faecium, P. acidilactici, L. plantarum, amylase, hemicellulase, and cellulase), Silobac $\AA^{(L . p l a n t a r u m, ~ S . ~ f a e c i u m, ~ a n d ~ L a c t o b a c i l l u s ~ s p .) ~ a n d ~ P i o n e e r ~ 1174 ® ~(S . ~ f a e c i u m ~ a n d ~ L . ~ p l a n t a r u m) . ~ S i l o s ~ w e r e ~ o p e n e d ~}$ 133 days after ensiling and sampled to proceed chemical analyses. Only in citrus pulp-free silage, all inoculants increased ethanol concentration; Pioneer increased $\mathrm{pH}$, and Silobac decreased acetic acid concentration, compared to control. Independently of citrus pulp, all inoculants decreased DM losses; Silobac ${ }^{\circledR}$ and Pioneer decreased IVDDM, and Pioneer increased $\mathrm{NH}_{3}-\mathrm{N}$. Inoculants did not influence lactic, propionic and butyric acids concentrations and neither aerobic stability. Citrus pulp improved chemical composition and fermentation characteristics, but worsened DM losses and aerobic stability.
\end{abstract}

Key Words: ensiling, lactic acid bacteria, organic acids, Medicago sativa

\section{Introdução}

No Brasil, é crescente o interesse pela utilização da alfafa na forma ensilada ou fenada. Segundo McAllister et al. (1998), embora a alfafa apresente alto valor nutritivo, são encontradas características indesejáveis para o adequado processo de fermentação. Nesta forrageira, o momento ideal de corte é quando $10-25 \%$ dos perfilhos se apresentam floridos. Entretanto, quando esta fase é obtida, a capacidade tampão está alta e os teores de carboidratos solúveis, baixos. Além disso, esta forrageira apresenta caule tubular e oco, que impede a adequada retirada do ar.

Diversos procedimentos vêm sendo pesquisados visando contornar esses problemas - uso de conservantes, como os ácidos fórmico e sulfúrico (Barry et al., 1980; Henderson \& McDonald, 1984; Haigh \& Parker, 1985), aditivos ricos em matéria seca e/ou carboidratos rapidamente fermentáveis (McCullough et al., 1960), emurchecimento ou uso de inoculantes microbianos (Cleale et al., 1990).

Visando o aumento da população de bactérias láticas no silo e, conseqüentemente, à maior produção de ácido lático, foram desenvolvidos os inoculantes

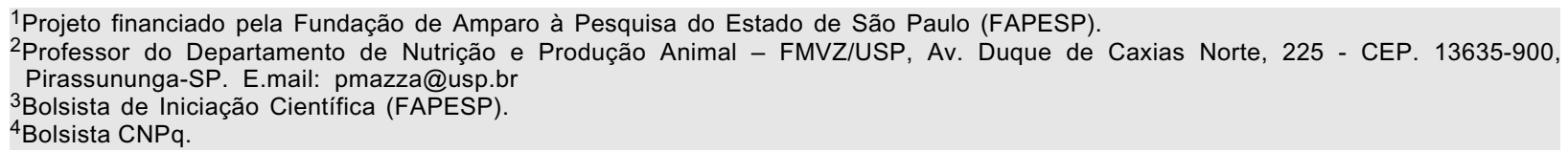


microbianos que são aplicados na forragem durante a ensilagem (Cleale et al., 1990). As mudanças esperadas com esse procedimento incluem rápido declínio no $\mathrm{pH}$, diminuição da concentração de nitrogênio amoniacal, por causa da inibição da proteólise, decréscimo nos níveis de acetato e butirato e incremento no conteúdo de ácido lático (Kung et al., 1984). Contudo, os efeitos da inoculação microbiana na silagem de alfafa são bastante variáveis (Bolsen et al., 1989). Em alguns estudos, a inoculação produziu pequena melhora na qualidade da silagem (Gordon, 1989), enquanto em outros tem produzido maior eficiência fermentativa, com redução das perdas de matéria seca, melhorando a digestibilidade (Rice et al., 1990) e o ganho de peso ou a produção leiteira (Gordon, 1989).

Nos últimos 5 a 10 anos, considerável atenção foi direcionada para o emprego da celulase, hemicelulase e amilase, como aditivos de silagens, pois sua função primária seria quebrar a parede celular (polissacarídeos) e o amido dos grãos, aumentando a disponibilidade de açúcares para ação dos lactobacilos (Chen et al., 1994).

O presente experimento foi conduzido com o objetivo de avaliar a influência da utilização de inoculantes microbianos e enzimo-microbianos na composição bromatológica e no perfil fermentativo da silagem de alfafa adicionada ou não de polpa cítrica.

\section{Material e Métodos}

As silagens foram confeccionadas nas dependências do Departamento de Nutrição e Produção Animal da Faculdade de Medicina Veterinária e Zootecnia da Universidade de São Paulo (Campus de Pirassununga). A alfafa utilizada foi cortada com 35 dias de crescimento, quando possuía $10 \%$ dos perfilhos laterais floridos, e picada em partículas de, aproximadamente, $2,5 \mathrm{~cm}$. O armazenamento foi realizado em 32 silos experimentais confeccionados a partir de baldes plásticos (252 mm de altura e $245 \mathrm{~mm}$ de diâmetro), que foram hermeticamente fechados por uma tampa portando válvula tipo "búnsen", para livre escape dos gases. Metade dos silos experimentais (16 silos) recebeu apenas a planta da alfafa tratada com os diferentes inoculantes (excetuando o controle) e outra metade (16 silos), além dos inoculantes, $12 \%$ de polpa cítrica peletizada, com base na matéria original.

Cada grupo de 16 silos experimentais (grupo com ou sem polpa) foi dividido em quatro grupos, sendo um controle e outros três preenchidos com a alfafa tratada com um dos inoculantes comerciais listados abaixo, formando um arranjo fatorial de tratamentos do tipo $2 \times 4$, correspondendo à ausência e presença de polpa e aos quatro grupos referentes aos inoculantes. Todos os inoculantes foram aplicados segundo recomendações do fabricante, procedendo-se à sua diluição com água destilada.

a) Sil-All®: produto à base de Streptococcus faecium, Pediococcus acidilactici e Lactobacillus plantarum, bem como amilase, hemicelulase e celulase, na dose de $10,0 \mathrm{mg}$ por $\mathrm{kg}$ de forragem; o produto possui $8,0 \times 10^{10}$ unidades formadoras de colônia/g.

b) SiloBac ${ }^{\circledR}$ : produto à base de L. plantarum, S. faecium e Lactobacillus sp. na dose de 2,0 mg por $\mathrm{kg}$ de forragem; o produto possui $5,26 \times 10^{10}$ unidades formadoras de colônia/g.

c) Pioneer 1174®: produto à base de S. faecium e L. plantarum na dose de $1,11 \mathrm{mg}$ por $\mathrm{kg}$ de forragem; o produto possui $9,0 \times 10^{10}$ unidades formadoras de colônia/g.

Aproximadamente $6 \mathrm{~kg}$ de massa úmida, adicionada ou não de polpa cítrica, foram colocados em cada silo. Estes foram compactados, fechados com as tampas portando válvula "búnsen" e, então, pesados. A compactação correspondeu a, aproximadamente, $500 \mathrm{~kg}$ de silagem $/ \mathrm{m}^{3}$, sendo os silos mantidos por 133 dias em local abrigado.

Antes da abertura, os silos foram pesados para posterior determinação das perdas de matéria seca. Uma vez abertos, as silagens de cada silo foram homogeneizadas, sendo uma parcela separada para determinação de matéria seca, em estufa de ventilação forçada $\left(65^{\circ} \mathrm{C}\right)$, proteína bruta (AOAC, 1980), componentes da parede celular (FDN e lignina, segundo Van Soest, 1967), carboidratos solúveis (Johnson et al., 1966), amido (Pereira \& Rossi, 1995), nitrogênio insolúvel em detergente ácido (Van Soest \& Robertson, 1985), capacidade tampão (Tosi, 1973) e digestibilidade in vitro da matéria seca (Tilley \& Terry, 1963). Para a análise de FDN, foram omitidos o sulfito de sódio e a $\alpha$-amilase. Outra fração foi colocada em prensa manual para extração dos sucos e imediata determinação do $\mathrm{pH}$ (medição em potenciômetro) e do nitrogênio amoniacal (Foldager, 1977). Parte do suco foi fixada e congelada para posterior determinação dos ácidos orgânicos por cromatografia gasosa (Erwin et al., 1961). 
Os cálculos das perdas por fermentação foram realizados pela diferença entre os pesos das massas obtidos no enchimento e na abertura dos silos, multiplicados pelos respectivos teores de matéria seca. Finalmente, as perdas foram transformadas em porcentagem da massa inicial.

Para determinação da estabilidade aeróbia da silagem, aproximadamente $2,0 \mathrm{~kg}$ de massa úmida foram retirados de cada balde e transferidos para caixas de isopor (5 litros), que foram armazenadas em local coberto e à temperatura ambiente, a fim de permitir tomadas de temperatura ambiental e da silagem às $0,12,24,48,72,96$ e 120 horas após a abertura dos silos, por meio de um termômetro inserido $10 \mathrm{~cm}$ dentro da massa contida na caixa de isopor. A estabilidade aeróbia foi calculada como uma taxa de elevação da temperatura, usando o máximo da temperatura observada dividida pelo tempo necessário para alcançar a máxima temperatura (Ruppel et al., 1995). Adicionalmente, foram avaliados a máxima temperatura alcançada $\left(\mathrm{em}^{\circ} \mathrm{C}\right)$ e o tempo para obtenção da máxima temperatura (em horas).

As diversas variáveis foram submetidas à análise de variância pelo procedimento GLM do Statistical Analysis System (SAS, 1985), que separou, como causas de variação, efeito de inoculante, efeito de polpa cítrica e interação. As médias foram comparadas pelo teste Tukey. Na presença de interação, a separação entre os tratamentos foi realizada dentro da variável presença de polpa. Para todas as análises, foi utilizado nível de significância de $5 \%$.

\section{Resultados e Discussão}

A cultura de alfafa e a polpa cítrica utilizadas para confecção das silagens está caracterizada na Tabela 1. A alfafa apresentou composição bromatológica compatível com o esperado, excetuando os valores de amido, que foram excessivamente altos. É possível que a metodologia descrita por Pereira \& Rossi (1995) superestime a concentração desse tipo de carboidrato, uma vez que esses autores não fazem menção à necessidade de se proceder à prévia extração dos carboidratos solúveis antes da determinação da glicose.

Os dados de composição químico-bromatológica das silagens resultantes dos diferentes tratamentos encontram-se na Tabela 2. Não foram identificadas diferenças significativas para os teores de matéria seca, quanto ao efeito de inoculante. Entretanto, a adição de polpa cítrica aumentou significativamente esse valor, como esperado. Cabe destacar que os possíveis efeitos da polpa sobre a fermentação não se baseiam apenas em sua capacidade de elevar a matéria seca da silagem, uma vez que esse material apresenta por volta de $85-90 \%$ de matéria seca, mas também na sua capacidade de absorver a água, aumentando a pressão osmótica do meio. Em razão da grande concentração de pectina, considerada por Van Soest (1994) como uma fibra solúvel, a polpa cítrica possui potencial de retenção de água em torno de $145 \%$ de seu peso (Carvalho, 1996).

Os valores encontrados para carboidratos solúveis na silagem não-tratada com polpa estão coerentes

Tabela 1 - Composição bromatológica dos ingredientes utilizados para ensilagem ${ }^{1}$ Table 1 - Chemical composition of the ingredients used for ensiling

\begin{tabular}{|c|c|c|c|c|c|c|c|c|}
\hline & $\begin{array}{l}\mathrm{MS} \\
D M\end{array}$ & $\begin{array}{l}\mathrm{PB} \\
C P\end{array}$ & $\begin{array}{l}\text { FDN } \\
N D F\end{array}$ & $\begin{array}{l}\text { Lig } \\
\text { Lig }\end{array}$ & $\begin{array}{l}\text { Amido } \\
\text { Starch }\end{array}$ & $\begin{array}{c}\text { CHOs } \\
W S C\end{array}$ & $\begin{array}{l}\text { DIVMS } \\
I V D D M\end{array}$ & $\begin{array}{l}\text { CT } \\
B C\end{array}$ \\
\hline $\begin{array}{l}\text { Alfafa } \\
\text { Alfalfa }\end{array}$ & 18,95 & 22,46 & 32,75 & 9,56 & 15,60 & 1,00 & 71,25 & 62,92 \\
\hline $\begin{array}{l}\text { Polpa cítrica } \\
\text { Citrus pulp }\end{array}$ & 86,50 & 7,35 & 25,75 & 5,00 & - & 25,96 & - & - \\
\hline
\end{tabular}

${ }^{1} \mathrm{MS}$ : matéria seca total (\%); PB: proteína bruta (\% MS); FDN: fibra em detergente neutro (\% MS); Lig.: lignina (\% MS); Amido (\% MS); CHOs: carboidratos solúveis (\% MS); DIVMS: digestibilidade in vitro da matéria seca (\% MS) e CT: capacidade tampão (meq/100 g MS de forragem).

${ }^{1}$ DM: dry matter (\%); CP: crude protein (\% DM); NDF: neutral detergent fiber (\% DM); Lig: lignin (\% DM); Starch (\% DM); WSC: water-soluble carbohydrate $(\%$ DM); IVDDM: in vitro digestibility of dry matter (\% DM); BC: buffering capacity (meq./100 $\mathrm{g}$ of DM). 
com os obtidos por McAllister et al. (1998), apesar ter sido usado $30 \%$ de florescimento para o corte da alfafa. Os teores de carboidratos solúveis não foram alterados significativamente pelo uso de inoculantes. Entretanto, quando adicionada a polpa, este teor foi elevado em torno de 3,0 pontos percentuais, resultando em diferença estatisticamente significativa. Este aumento também já era esperado, uma vez que a polpa cítrica é rica em carboidratos solúveis (Carvalho, 1996).

Alteração dos valores de NIDA, FDN e DIVMS, com a adição da polpa, já era esperada, em virtude da composição desse material. A adição da polpa aumentou o teor da lignina, provavelmente em decorrência de um erro de técnica, em que a pectina precipitaria na presença da solução de detergente ácido. No presente experimento, foi utilizada a técnica da lignina em permanganato, embora seja esperado o mesmo erro com a determinação da lignina em ácido clorídrico. $\mathrm{O}$ tratamento seqüencial com solução de detergente neutro, seguido pelo tratamento com detergente ácido, parece também ser recomendado para determinação da lignina em alimentos ricos em pectina.

Os inoculantes Sil-All e Pioneer diminuíram significativamente os teores de $\mathrm{PB}(\mathrm{N} \times 6,25)$ da silagem, em relação ao controle, independentemente da presença de polpa cítrica. Tal resposta é compatível com o incremento numérico causado pelo Sil-All e aumento estatisticamente significativo causado pelo Pioneer sobre as concentrações de nitrogênio amoniacal. É possível que o nitrogênio solubilizado durante a fermentação tenha sido perdido durante a secagem da silagem na estufa, resultando em menores teores de PB nesses tratamentos.

A digestibilidade in vitro da silagem de alfafa não adicionada de polpa cítrica apresentou valores compatíveis aos encontrados por Meeske (1998). Observou-se que os inoculantes Silobac e Pioneer diminuíram a digestiblidade in vitro da MS da silagem, independentemente da adição de polpa, resultados que discordam dos obtidos por Mader et al. (1985). Esses autores verificaram aumento da digestibilidade in vitro da MS da silagem de alfafa inoculada, provavelmente em decorrência da maior concentração de componentes voláteis (nitrogênio amoniacal e o etanol), na silagem tratada com esses inoculantes, uma vez que a metodologia para determinação da DIVMS exige a secagem prévia da amostra.
Entretanto, a adição de polpa cítrica aumentou significativamente os coeficientes de digestibilidade do material ensilado, o que era esperado, uma vez que a polpa cítrica apresenta, segundo Carvalho (1996), digestibilidade da matéria seca de $78,6 \%$, enquanto no presente experimento, a planta de alfafa apresentou, digestibilidade de $71,25 \%$. Aumento da digestibilidade da silagem adicionada de polpa é compatível com a inclusão de $12 \%$ de polpa na alfafa, representando, aproximadamente, $45 \%$ da matéria seca ensilada.

Os dados de avaliação do perfil fermentativo das silagens encontram-se na Tabela 3. Identificou-se interação entre os inoculantes e a adição de polpa cítrica, sendo que, na ausência de polpa, a silagem tratada com o inoculante Pioneer apresentou maior $\mathrm{pH}$ que a silagem controle, sem, no entanto, diferir da silagem tratada com os demais inoculantes. Entretanto, quando se adicionou $12 \%$ de polpa cítrica ao material, o efeito de inoculante não ocorreu, o que poderia ser justificado pela maior presença de carboidratos solúveis e por maiores teores de matéria seca no momento da ensilagem. Com a elevação desses dois fatores limitantes, as bactérias teriam um meio ideal para multiplicação e produção de ácidos orgânicos, igualando as respostas entre os tratamentos. Embora a velocidade de queda do $\mathrm{pH}$ das silagens não tenha sido avaliada nesse experimento, a queda mais rápida no $\mathrm{pH}$ das silagens tratadas com polpa também poderia ser responsável pelos menores níveis de nitrogênio amoniacal nestas silagens, provavelmente pela rápida inibição da proteólise e/ou da ação de bactérias secundárias, como aquelas do gênero Clostridium sp. (Muck, 1987). Observou-se interação entre os inoculantes e a adição de polpa também para as concentrações de etanol e ácido acético. As concentrações de etanol elevaram-se, em média, mais de 6 vezes, em relação ao controle, quando a silagem recebeu a adição de inoculante. Chamberlain (1987) postulou que a rápida acidificação durante as primeiras fases da fermentação poderia favorecer o desenvolvimento de leveduras e promover, portanto, a fermentação de açúcares residuais a etanol, em razão de algumas espécies de leveduras serem altamente resistentes às condições de baixo $\mathrm{pH}$. Entretanto, este fato não foi observado nesta pesquisa, uma vez que os inoculantes elevaram o $\mathrm{pH}$ das silagens, em vez de diminuir. Adicionalmente, esta diferença causada pelos inoculantes não 
Tabela 2 - Composição bromatológica das silagens submetidas aos diferentes tratamentos ${ }^{1}$ Table 2 - Chemical composition of silages submitted to different treatments

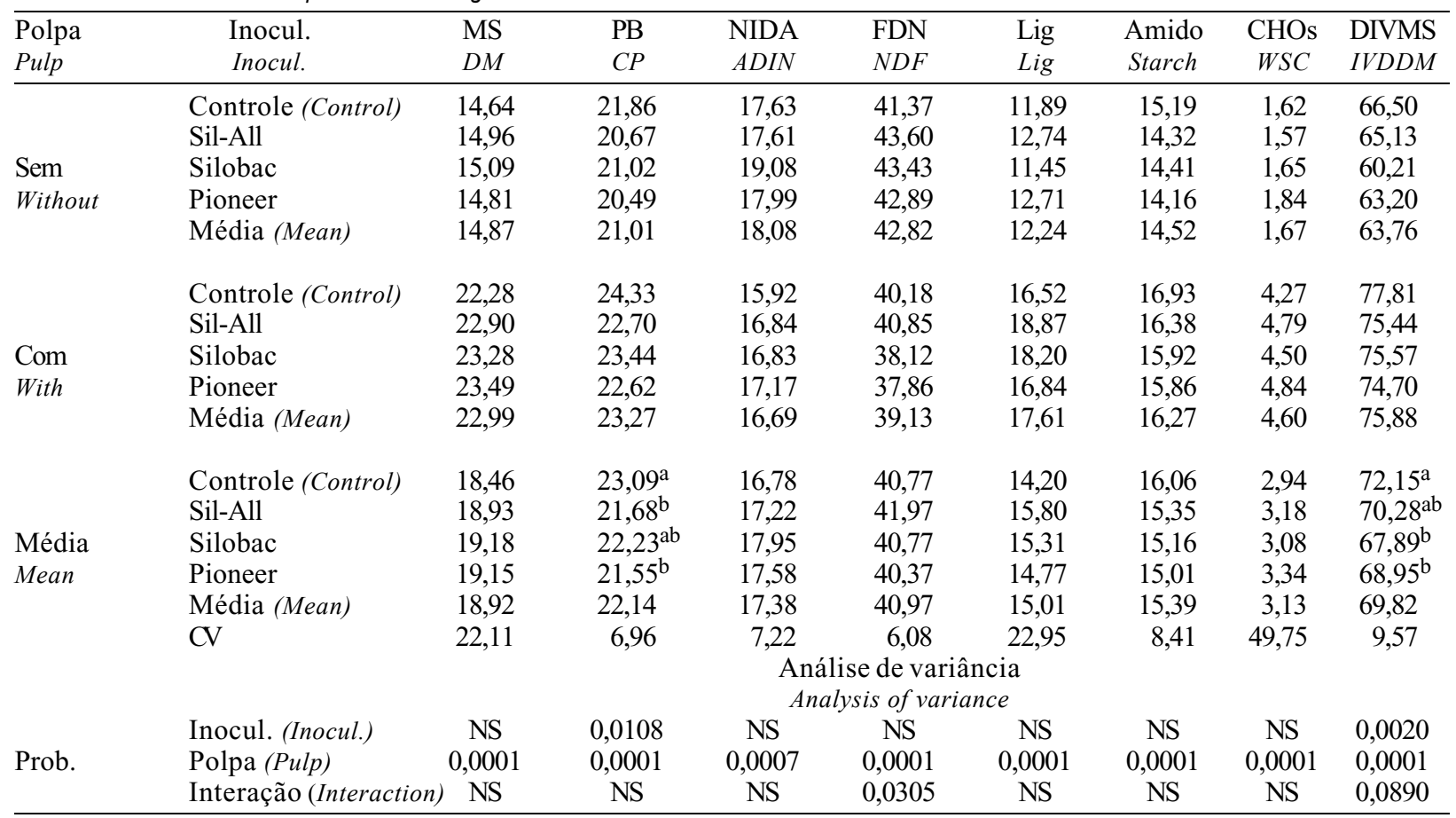

${ }^{1}$ MS: matéria seca total (\%); PB: proteína bruta (\% MS); NIDA: nitrogênio insolúvel em detergente ácido (\% do N total); FDN: fibra em detergente neutro (\% MS); Lig: lignina (\% MS); Amido (\% MS); CHOs: carboidratos solúveis (\% MS); DIVMS: digestibilidade in vitro da matéria seca (\% MS); CV: coeficiente de variação (\%); Prob.: probabilidade estatística para efeito de inoculante (Inocul.), polpa cítrica e interação; NS: não-significativo.

${ }^{1}$ DM: dry matter (\%); CP: crude protein (\% DM); ADIN: acid detergent insoluble nitrogen (\% of total N); NDF: neutral detergent fiber (\% DM); Lig: lignin (\% DM); Starch (\% DM); WSC: water-soluble carbohydrate (\% DM); IVDDM: in vitro digestibility of dry matter (\% DM); CV: coefficient of variation (\%); Prob: statistical probability for effect of inoculant (Inocul.), citrus pulp, and interaction; NS: not significant.

Colunas com letras sobrescritas diferentes dentro de adição de polpa diferem pelo teste Tukey (5\%).

Columns with different letters inside citrus pulp differ by Tukey test (5\%).

se manteve na presença polpa cítrica. Possivelmente, a maior velocidade de redução do $\mathrm{pH}$ pode ter contornado os efeitos de aumento da produção de etanol pela ação dos microrganismos presentes.

A adição do inoculante Silobac, bem como da polpa cítrica, reduziu significativamente a produção de ácido acético. Como os inoculantes não causaram respostas significativas sobre as concentrações dos ácidos propiônico, butírico e lático, provavelmente em virtude do alto coeficiente de variação observado, a adição de polpa melhorou significativamente todos esses parâmetros, resultando também em queda da capacidade tampão das silagens. Segundo McDonald et al. (1991), os ácidos acético e lático são os principais componentes determinantes da capacidade tampão da silagem já fermentada. Ressalta-se que as silagens tratadas com polpa apresentam os maiores níveis de ácido lático e as menores capacidades tampão, apesar dos menores níveis de ácido acético, provavelmente por um efeito da pectina.

Os dados obtidos neste estudo discordam dos observados por Kung et al. (1991) e Cai et al. (1999), que observaram aumentos significativos nas concentrações do ácido lático com o uso de inoculantes. Entretanto, Bolsen et al. (1992) demonstraram somente efeitos positivos sobre este parâmetro quando combinaram inoculante mais glicose, mas não quando utilizaram inoculante microbiano (L. plantarum e $P$. cerevisiae) ou glicose ( $2 \%$ da MS) separadamente. Embora estatisticamente não-significativo, aparentemente os inoculantes tenderam a aumentar as concentrações de ácido lático ou a relação lático:acético, 
Tabela 3 - Fermentação das silagens submetidas aos diferentes tratamentos ${ }^{1}$ Table 3 - Fermentation pattern of silages submitted to different treatments

\begin{tabular}{|c|c|c|c|c|c|c|c|c|c|c|}
\hline $\begin{array}{l}\text { Polpa } \\
\text { Pulp }\end{array}$ & $\begin{array}{l}\text { Inocul. } \\
\text { Inocul. }\end{array}$ & $\mathrm{pH}$ & $\mathrm{N}-\mathrm{NH}_{3}$ & $\begin{array}{l}\text { CT } \\
B C\end{array}$ & $\begin{array}{l}\text { Etanol } \\
\text { Ethanol }\end{array}$ & $\begin{array}{c}\text { Acético } \\
\text { Acetic }\end{array}$ & $\begin{array}{l}\text { Prop. } \\
\text { Prop. }\end{array}$ & $\begin{array}{l}\text { Butír. } \\
\text { Butiric }\end{array}$ & $\begin{array}{l}\text { Lático } \\
\text { Lactic }\end{array}$ & $\mathrm{L} / \mathrm{A}$ \\
\hline \multirow{5}{*}{$\begin{array}{l}\text { Sem } \\
\text { Without }\end{array}$} & Controle (Control) & $5,50^{\mathrm{b}}$ & 29,48 & 123,22 & $0,464^{\mathrm{b}}$ & $10,291^{\mathrm{a}}$ & 0,286 & 0,985 & 1,158 & 0,111 \\
\hline & Sil-All & $5,93^{\mathrm{ab}}$ & 35,67 & 133,85 & $3,080^{\mathrm{a}}$ & $8,361^{\mathrm{ab}}$ & 0,338 & 1,724 & 4,534 & 0,542 \\
\hline & Silobac & $5,86^{\mathrm{ab}}$ & 32,79 & 123,99 & $2,744^{\mathrm{a}}$ & $6,591^{b}$ & 0,355 & 2,365 & 3,595 & 0,567 \\
\hline & Pioneer & $6,11^{\mathrm{a}}$ & 37,27 & 123,84 & $2,903^{\mathrm{a}}$ & $7,923^{\mathrm{ab}}$ & 0,410 & 2,851 & 0,952 & 0,121 \\
\hline & Média (Mean) & 5,85 & 33,80 & 126,22 & 2,344 & 8,405 & 0,347 & 1,981 & 2,559 & 0,320 \\
\hline \multirow{5}{*}{$\begin{array}{l}\text { Com } \\
\text { With }\end{array}$} & Controle (Control) & 4,25 & 26,72 & 51,43 & 0,614 & 3,900 & 0,136 & 0,014 & 9,150 & 2,397 \\
\hline & Sil-All & 4,22 & 29,03 & 51,39 & 0,454 & 3,610 & 0,082 & 0,011 & 11,251 & 3,266 \\
\hline & Silobac & 4,27 & 28,18 & 50,27 & 0,513 & 3,930 & 0,086 & 0,009 & 13,825 & 3,742 \\
\hline & Pioneer & 4,28 & 29,11 & 47,41 & 0,380 & 3,891 & 0,100 & 0,024 & 10,433 & 3,023 \\
\hline & Média (Mean) & 4,25 & 28,26 & 50,12 & 0,490 & 3,832 & 0,102 & 0,014 & 11,167 & 3,107 \\
\hline \multirow{6}{*}{$\begin{array}{l}\text { Média } \\
\text { Mean }\end{array}$} & Controle (Control) & 4,88 & $28,10^{\mathrm{b}}$ & 87,32 & 0,550 & 7,095 & 0,211 & 0,499 & 5,154 & 1,254 \\
\hline & Sil-All & 5,08 & $32,35^{\mathrm{ab}}$ & 92,62 & 1,580 & 5,985 & 0,210 & 0,868 & 7,892 & 1,904 \\
\hline & Silobac & 5,06 & $30,49^{\mathrm{ab}}$ & 87,13 & 1,469 & 5,070 & 0,240 & 1,187 & 8,710 & 2,381 \\
\hline & Pioneer & 5,19 & $33,19^{\mathrm{a}}$ & 85,63 & 1,641 & 5,907 & 0,255 & 1,438 & 5,697 & 1,572 \\
\hline & Média (Mean) & 5,05 & 31,03 & 88,17 & 1,321 & 6,045 & 0,228 & 0,999 & 6,863 & 1,758 \\
\hline & $\mathrm{CV}$ & 16,71 & 15,17 & 44,42 & 90,10 & 44,29 & 62,40 & 131,83 & 80,37 & 100,79 \\
\hline \multicolumn{11}{|c|}{$\begin{array}{l}\text { Análise de variância } \\
\text { Analysis of variance }\end{array}$} \\
\hline \multirow{3}{*}{ Prob. } & Inocul. (Inocul.) & 0,0274 & 0,0201 & NS & 0,0001 & 0,0282 & NS & NS & NS & NS \\
\hline & Polpa (Pulp) & 0,0001 & 0,0001 & 0,0001 & 0,0001 & 0,0001 & 0,0001 & 0,0001 & 0,0001 & 0,0001 \\
\hline & Interação (Interaction) & 0,0384 & NS & NS & 0,0001 & 0,0258 & $\mathrm{NS}$ & NS & NS & NS \\
\hline
\end{tabular}

${ }^{1} \mathrm{~N}-\mathrm{NH}_{3}$ : nitrogênio amoniacal (\% do $\mathrm{N}$ total); CT: capacidade tampão (meq/100 g MS de forragem); Etanol (\% MS); Acético (\% MS); Prop.: propiônico (\% MS); Butír.: butírico (\% MS); Lático (\% MS); L/A: relação lático:acético; CV: coeficiente de variação (\%); Prob.: probabilidade estatística para efeito de inoculante (Inocul.), polpa cítrica e interação; NS: não-significativo.

${ }^{1} \mathrm{NH}_{3}-\mathrm{N}$ : ammoniacal nitrogen (\% of total N); BC: buffering capacity (meq./100 g of DM); Ethanol (\% DM); Acetic (\% DM); Prop.: propionic (\% DM); Butyric (\% DM); Lactic (\% DM); L/A: lactic/acetic ratio; CV: coefficient of variation (\%); Prob: statistical probability for effect of inoculant (Inocul.), citrus pulp, and interaction; NS: not significant.

Colunas com letras sobrescritas diferentes dentro de adição de polpa diferem pelo teste Tukey (5\%).

Column with different letters inside citrus pulp differ by Tukey test (5\%).

preferencialmente na silagem sem a adição de polpa. É possível que condições mínimas de fermentabilidade sejam necessárias para alcançar respostas com o uso de inoculantes, porém excelentes condições, como as promovidas pela adição de polpa, podem ter inibido o aparecimento das respostas positivas com esse aditivo.

Os inoculantes Silobac e Pioneer diminuíram significativamente as perdas por fermentação, independentemente da presença de polpa cítrica (Tabela 4). Embora não tenha sido observado efeito de interação entre o inoculante e a presença de polpa, os dados aparentam demonstrar maiores respostas positivas ao uso de inoculantes nas silagens não tratadas com polpa do que naquelas tratadas. Esse achado corrobora a hipótese de que condições ótimas de fermentação inibem as respostas alcançadas com os inoculantes.
Aumento das perdas por fermentação, observado com a adição da polpa, independentemente do tipo de inoculante, não é compatível com o conceito de que a fermentação heterolática, com a produção de ácido acético, acarreta perdas maiores que a fermentação homolática, com a produção de ácido lático. No presente experimento, as silagens adicionadas de polpa apresentaram as maiores perdas, mesmo com níveis mais baixos de $\mathrm{N}-\mathrm{NH}_{3}$, etanol, acético, propiônico e butírico.

Com relação à estabilidade aeróbia, o aumento da temperatura máxima alcançada e da taxa de elevação da temperatura observada com a adição da polpa cítrica parece concordar com a afirmação de Rust et al. (1989), de que o aumento das concentrações de ácido lático, resultado do incremento da fermentação do tipo homofermentativa, poderia resultar em silagens 
Tabela 4 - Perdas por fermentação e estabilidade aeróbia das silagens submetidas à aplicação de inoculantes ${ }^{1}$ Table 4 - Fermentation losses and aerobic stability of inoculated silages

\begin{tabular}{|c|c|c|c|c|c|}
\hline $\begin{array}{l}\text { Polpa } \\
\text { Pulp }\end{array}$ & $\begin{array}{l}\text { Inocul. } \\
\text { Inocul. }\end{array}$ & $\begin{array}{l}\text { Perdas } \\
\text { Losses }\end{array}$ & $\begin{array}{l}\text { Tempo } \\
\text { Period }\end{array}$ & $\begin{array}{l}\text { Max. } \\
\text { Max. }\end{array}$ & $\begin{array}{l}\text { Taxa } \\
\text { Rate }\end{array}$ \\
\hline & Controle (Control) & 9,49 & 96,00 & 27,00 & 0,017 \\
\hline & Sil-All & 2,71 & 96,00 & 27,33 & 0,021 \\
\hline Sem & Silobac & 1,33 & 96,00 & 27,25 & 0,023 \\
\hline \multirow[t]{4}{*}{ Without } & Pioneer & 2,07 & 96,00 & 26,50 & 0,017 \\
\hline & Média (Mean) & 3,90 & 96,00 & 27,00 & 0,019 \\
\hline & Controle (Control) & 11,67 & 96,00 & 29,25 & 0,044 \\
\hline & Sil-All & 9,55 & 96,00 & 28,63 & 0,038 \\
\hline Com & Silobac & 8,18 & 96,00 & 28,50 & 0,036 \\
\hline \multirow[t]{4}{*}{ With } & Pioneer & 7,18 & 96,00 & 28,50 & 0,039 \\
\hline & Média (Mean) & 9,14 & 96,00 & 28,72 & 0,039 \\
\hline & Controle (Control) & $10,58^{\mathrm{a}}$ & 96,00 & 28,13 & 0,031 \\
\hline & Sil-All & $6,13^{\mathrm{ab}}$ & 96,00 & 28,07 & 0,031 \\
\hline \multirow[t]{6}{*}{ Média (Mean) } & Silobac & $4,75^{b}$ & 96,00 & 27,88 & 0,030 \\
\hline & Pioneer & $4,62^{b}$ & 96,00 & 27,50 & 0,028 \\
\hline & Média (Mean) & 6,52 & 96,00 & 27,89 & 0,030 \\
\hline & $\mathrm{CV}$ & 72,62 & - & 4,21 & 45,49 \\
\hline & & & $\begin{array}{c}\text { Análise de variância } \\
\text { Analysis of variance }\end{array}$ & & \\
\hline & Inocul. (Inocul.) & 0,0040 & NS & NS & NS \\
\hline \multirow[t]{2}{*}{ Prob. } & Polpa (Pulp) & 0,0001 & NS & 0,0001 & 0,0001 \\
\hline & Interação (Interaction) & NS & NS & NS & NS \\
\hline
\end{tabular}

${ }^{1}$ Perdas: perdas de matéria seca (\%); Tempo: tempo decorrido para alcançar a máxima temperatura (horas); Max.: máxima temperatura alcançada $\left({ }^{\circ} \mathrm{C}\right)$; Taxa: taxa de elevação da temperatura $\left({ }^{\circ} \mathrm{C} /\right.$ hora); CV: coeficiente de variação (\%); Prob.: probabilidades estatísticas para efeito de inoculante (Inocul.), polpa cítrica e interação; NS: não-significativo.

${ }^{1}$ Losses: dry matter losses (\%); Period: period of time to reach maximum temperature (hours); Max.: maximum temperature ( ${ }^{\circ} \mathrm{C}$ ); Rate: rate of increasing temperature ( ${ }^{\circ} \mathrm{C} /$ hour); CV: coefficient of variation (\%); Prob: statistical probability for effect of inoculant (Inocul.), citrus pulp, and interaction; NS: not significant.

Colunas com letras sobrescritas diferentes dentro de adição de polpa diferem pelo teste Tukey (5\%).

Column with different letters inside citrus pulp differ by Tukey test (5\%).

menos estáveis à deterioração aeróbia, quando da abertura do silo. Os dados deste estudo demonstram a necessidade de maiores cuidados no manejo de descarregamento do silo, ao se adicionar aditivos ricos em carboidratos rapidamente disponíveis, como é o caso da polpa cítrica peletizada. Possivelmente, não foi observada resposta aos inoculantes, pois, na ausência de polpa, cuja condição aparente propicia maiores respostas a estes produtos, a fermentação indesejável, representada pelo excesso de butírico e/ou de propiônico, garantiu boa estabilidade aeróbia. Entretanto, na presença de polpa, cuja condição favoreça problemas com a estabilidade aeróbia, em virtude do excesso de carboidratos solúveis residuais, os microrganismos adicionados teriam que competir com microbiota epifítica favorecida pela alta disponibilidade de carboidratos prontamente disponíveis.

\section{Conclusões}

Alterações no perfil fermentativo e diminuição das perdas por fermentação, promovidas pelos inoculantes microbianos, são mais evidentes em silagens sem adição de polpa cítrica.

A adição de polpa cítrica no nível de $12 \%$, com base na matéria verde da alfafa, permitiu fermentação mais compatível com a alta qualidade da forragem, embora esse tratamento possa aumentar as perdas por fermentação e diminuir a estabilidade aeróbia da silagem.

\section{Agradecimento}

À Fundação de Amparo à Pesquisa do Estado de São Paulo (FAPESP), pelo financiamento do projeto; aos funcionários Everson Lázaro e Gilmar Botteon 
pelo cuidado com a cultura; e aos técnicos Ari de Castro, Gilson de Godoy e Simi Robassini, pelas análises laboratoriais.

\section{Literatura Citada}

ASSOCIATION OF OFFICIAL ANALYTICAL CHEMISTS AOAC. Official methods of analysis. 10.ed. Washington, D.C.: 1980. $1015 \mathrm{p}$.

BARRY, T.N.; DIMENNA, M.E.; WEBB, P.R. et al. Some observations on aerobic deterioration of untreated silages and in silages made with formaldehyde containing additives. Journal of Science of Food and Agriculture, v.31, n.1, p.133, 1980.

BOLSEN, K.K.; LIN, C.; BRENT, B.E. et al. Effect of silage additives on the microbial succession and fermentation process of alfalfa and corn silages. Journal of Dairy Science, v.75, n.11, p.3066-3083, 1992.

BOLSEN, K.K.; LAYTINI, A.; HART, R.A. et al. Effect of commercial inoculants on fermentation of 1987 and 1988. Kansas silage crops. Des Moines: Pionner Hi-Bred Int., 1989. p.1-19.

CAI, Y.; BENNO, Y.; OGAWA, M. et al. Effect of applying lactic acid bacteria isolated from forage crops on fermentation characteristics and aerobic deterioration of silage. Journal of Dairy Science, v.82, n.3, p.520-526, 1999.

CARVALHO, M.P. Citrus. In: SIMPÓSIO SOBRE NUTRIÇÃO DE BOVINOS, 6., 1996, Piracicaba. Anais... Piracicaba: Fundação de Estudos Agrários Luiz de Queiroz, 1996. p.171- 214.

CHAMBERLAIN, D.G. The silage fermentation in relation to the utilization of nutrients in the rumen. Process Biochemistry, v.4, n.1, p.60-63, 1987.

CHEN, J.; STOKES, M.R.; WALLACE, C.R. Effects of enzymeinoculant systems on preservation and nutritive value of haycrop and corn silages. Journal of Dairy Science, v.77, n.2, p.501-512, 1994.

CLEALE, R.M.; FIRKINS, J.L.; Van De BEEK, F. et al. Effect of inoculation of whole plant corn forage with Pediococcus acidilactili and Lactobacillus xylosus on preservation of silage and heifer growth. Journal of Dairy Science, v.73, n.3, p.711-718, 1990

ERWIN, E.S.; MARCO, G.J.; EMERY, E.M. Volatile fatty acid analyses of blood and rumen fluid by gas chromatography. Journal of Dairy Science, v.44, n.9, p.1768-1771, 1961.

FOLDAGER, J. Protein requeriment and non protein nitrogen for high producing cow in early lactation. East Lasing: Michigan State University, 1977. 167p. Tese (Doutorado em Ciência Animal) - Michigan State University, 1977.

GORDON, F.J. A further study on the evaluation through lactating cattle of a bacterial inoculant as an additive for grass silage. Grass and Forage Science, v.44, n.3, p.353-357, 1989.

HAIGH, P.M.; PARKER, J.W.G. Effect of silage additives and wilting on silage fermentation, digestibility and intake, and on live weight chances of young cattle. Grass and Forage Science, v.40, n.2, p.429, 1985 .

HENDERSON, A.R.; McDONALD, P. The effect of range of commercial inoculants on the biochemical changes during the ensilage of grass in laboratory studies. Research and Development in Agriculture, v.1, n.1, p.171, 1984.

JOHNSON, R.R.; BALWANI, T.L.; JOHNSON, L.J. et al. Corn plant maturity. II. Effect on in vitro cellulose digestibility and soluble carbohydrates content. Journal of Animal Science, v.25, n.3, p.617-623, 1966.
KUNG JR., L.; TUNG, R.S.; MACIOROWSKI, K.G. et al. Effects of plant cell-wall-degrading enzymes and lactic acid bacteria on silage fermentation and composition. Journal of Dairy Science, v.74, n.12, p.4284-4296, 1991.

KUNG JR., L.; GRIEVE, D.B.; THOMAS, J.W. et al. Added ammonia as microbial inoculant for fermentation and nitrogenous compounds of alfalfa ensiled at various percents of dry matter. Journal of Dairy Science, v.67, n.2, p. 299-306, 1984.

MADER, T.L.; BRITTON, R.A.; KRAUSE, V.E. Effects of additive on alfalfa silage fermentation characteristics and feedlot performance of steers. Journal of Dairy Science, v.68, n.7, p.1744-1747, 1985.

McALLISTER, T.A.; FENIUK, R.; MIR, P. et al. Inoculants for alfalfa silage: Effects on aerobic stability, digestibility and growth performance of feedlot steers. Livestock Production Science, v.53, n.1, p.171-181, 1998.

McCULLOUGH, M.E.; SISK, L.R.; SELL, O.E. Influence of preservatives on the fermentation, nutrient recovery, and feeding value of alfalfa, star millet and cowpea and sudan grass silages. Journal of Dairy Science, v.43, n.5, p.1827-1837, 1960.

McDONALD, P.; HENDERSON, A.R.; HERON, S.J.E. The biochemistry of silage. 1.ed. Marlow: Chalcombe Publications, 1991. 219p.

MEESKE, R. The effect of an inoculant on the preservation of tropical grass (Eragrostis curvula) and Lucerne (Medicago sativa) in South Africa. In: ALLTECH'S FOURTEENTH ANNUAL SYMPOSIUM, 14., 1998, Nottingham, Proceedings... Nottingham, 1998. p.145-155.

MUCK, R.E. Dry matter level effects on alfalfa silage quality. Transactions of the American Society in Agriculture and Engineering, v.30, n.1, p.7-11, 1987.

PEREIRA, J.R.A.; ROSSI JR., P. Manual prático de avaliação nutricional de alimentos. 1.ed. Piracicaba: Fundação de Estudos Agrários "Luiz de Queiroz", 1995. 25p.

RICE, D.W.; SODERLUND, S.D.; PHILLIP, I.E. et al. Effect of microbial inoculant on the digestibility of legume silages. Journal of Dairy Science, v.73, n.1, p.195-199, 1990.

RUPPEL, K.A.; PITT, R.E.; CHASE, L.E. Bunker silo management and its relationship to forage preservation on dairy farms. Journal of Dairy Science, v.78, n.1, p.141-153, 1995.

RUST, S.R.; KIM, H.S.; ENDERS, G.L. Effects of microbial inoculant on fermentation characteristics and nutritive value of corn silage. Journal of Production and Agriculture, v.2, n.1, p.235-241, 1989.

STATISTICAL ANALYSES SYSTEM - SAS. SAS user's guide: statistics. 5.ed. Cary: 1985.

TILLEY, J.M.A.; TERRY, R.A. A two-stage technique for the in vitro digestion of forage crops. Journal of British Grassland Society, v.18, n.2, p.104-111, 1963.

TOSI, H. Ensilagem de gramíneas tropicais sob diferentes tratamentos. Jaboticabal: Universidade Estadual de São Paulo, 1973. 107p. Tese (Doutorado) - Universidade Estadual de São Paulo, 1973.

Van SOEST, P.J. Development of a comprehensive system for analysis and its application to forage. Journal of Animal Science, v.26, n.1, p.119-128, 1967.

Van SOEST, P.J.; ROBERTSON, J.B. Analysis of forages and fibrous foods. 1.ed. Ithaca: Cornell University, 1985. 202p.

Van SOEST, P.J. Nutritional ecology of the ruminant. 2.ed. Ithaca: Cornell University, 1994. 476p.

Recebido em: 03/02/03 Aceito em: $25 / 05 / 04$

R. Bras. Zootec., v.33, n.6, p.1646-1653, 2004 (Supl. 1) 